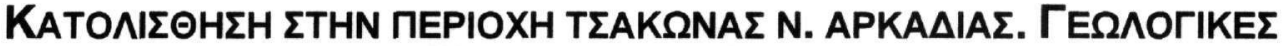

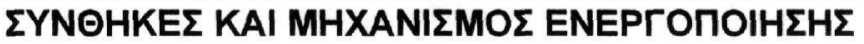

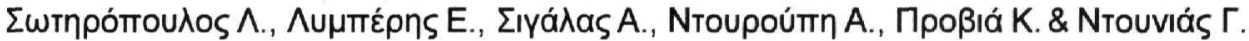

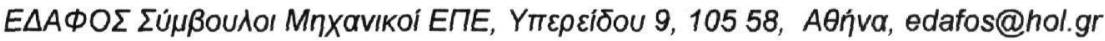

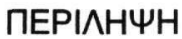

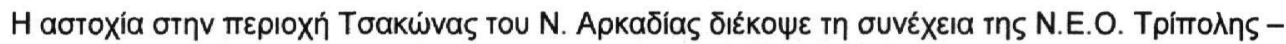

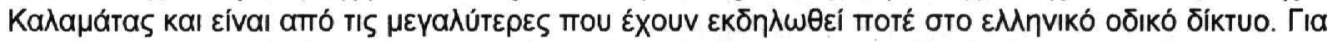

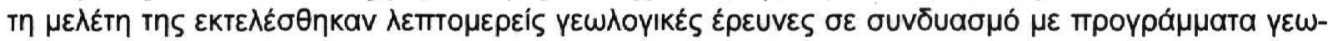

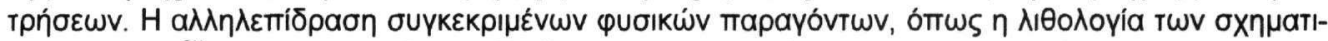

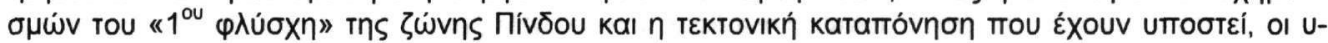

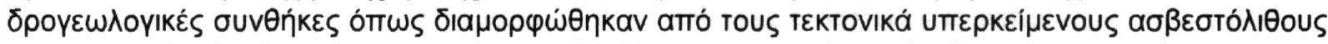

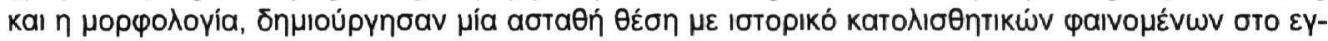

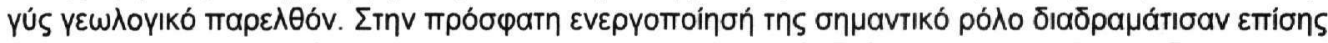

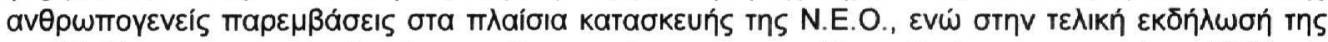

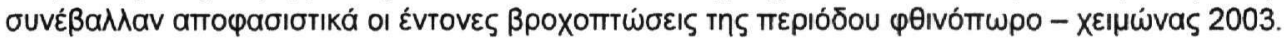

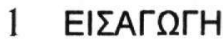

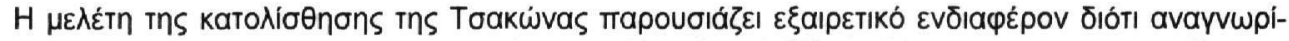

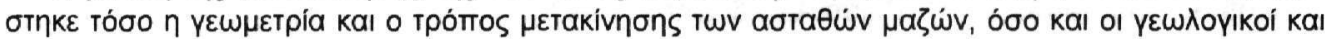

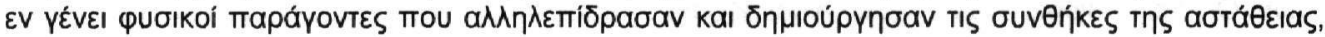

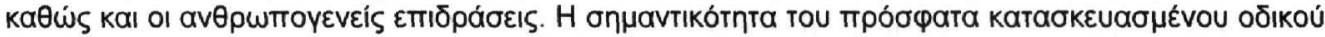

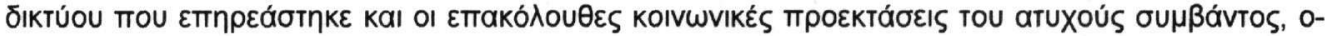

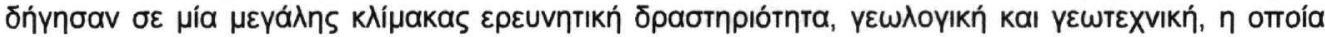

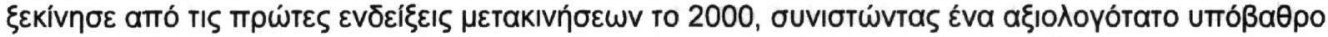

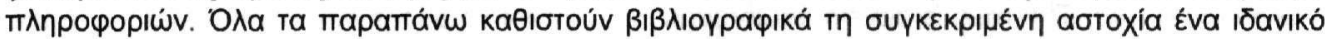

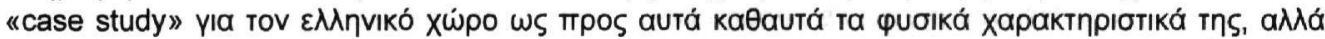

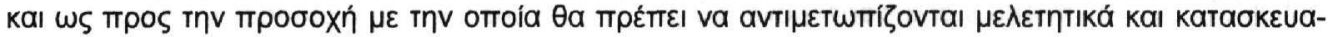

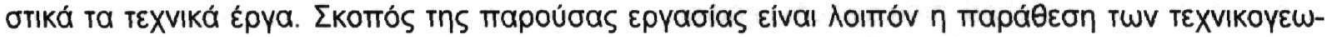

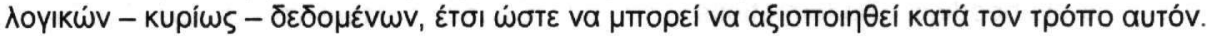

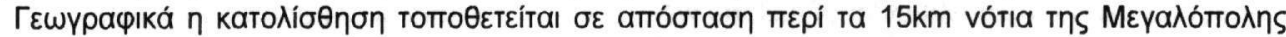

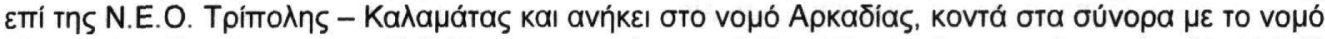

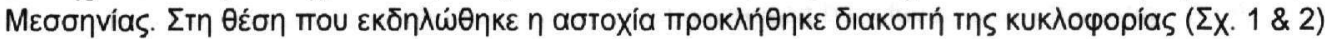
$\eta$ отоі́⿱㇒⿻

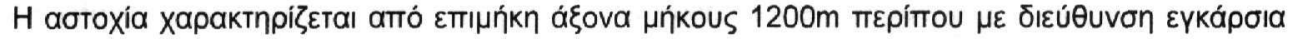

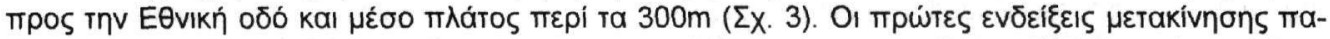

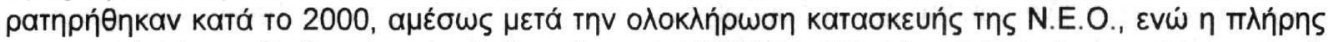

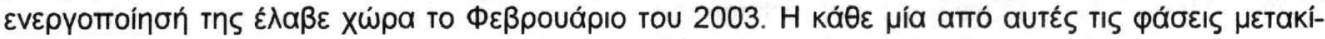

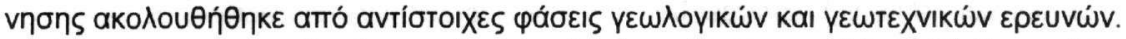

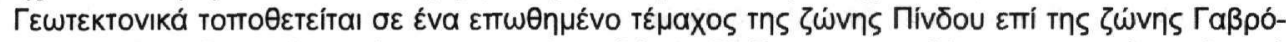

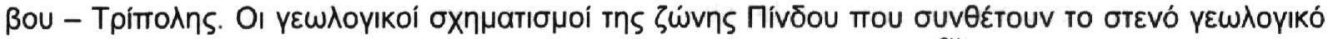

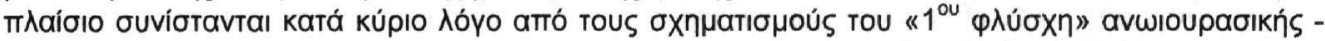

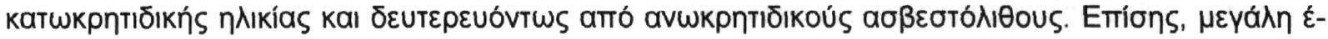

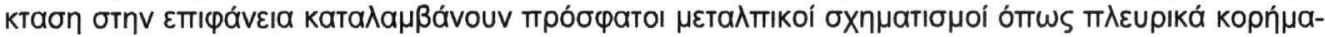

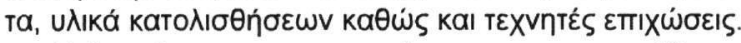

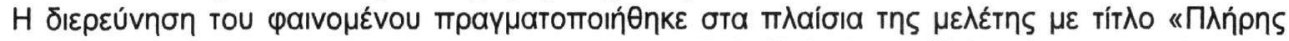

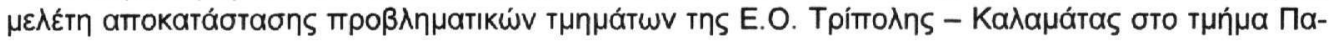




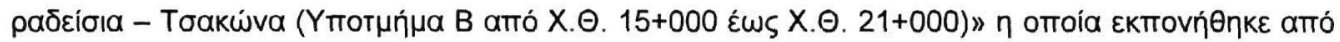

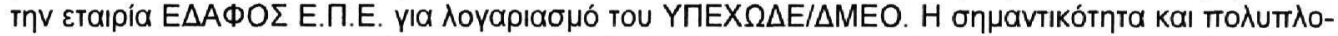

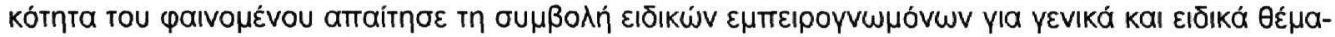

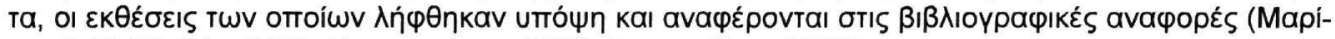

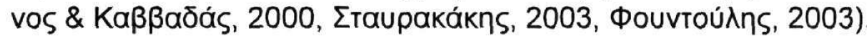

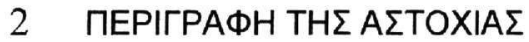

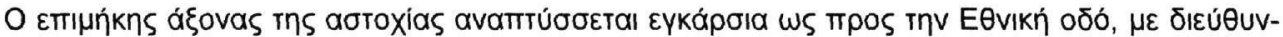

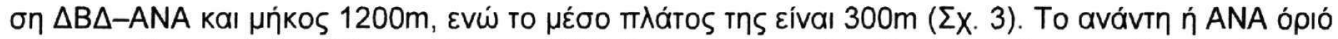

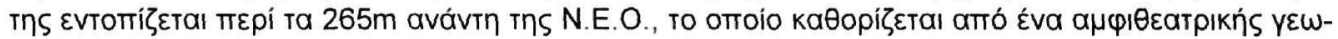

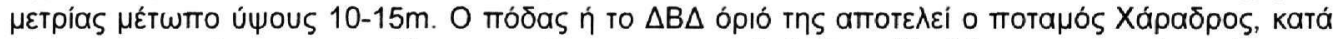

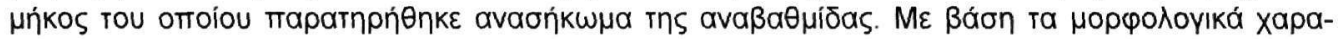

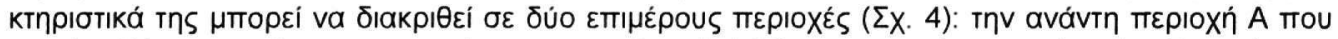

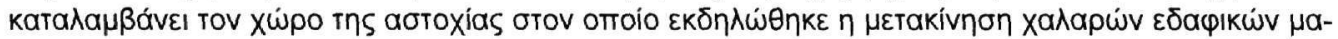

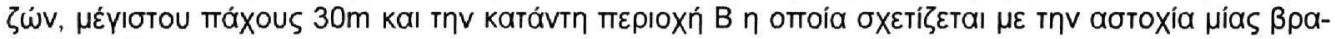

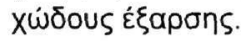

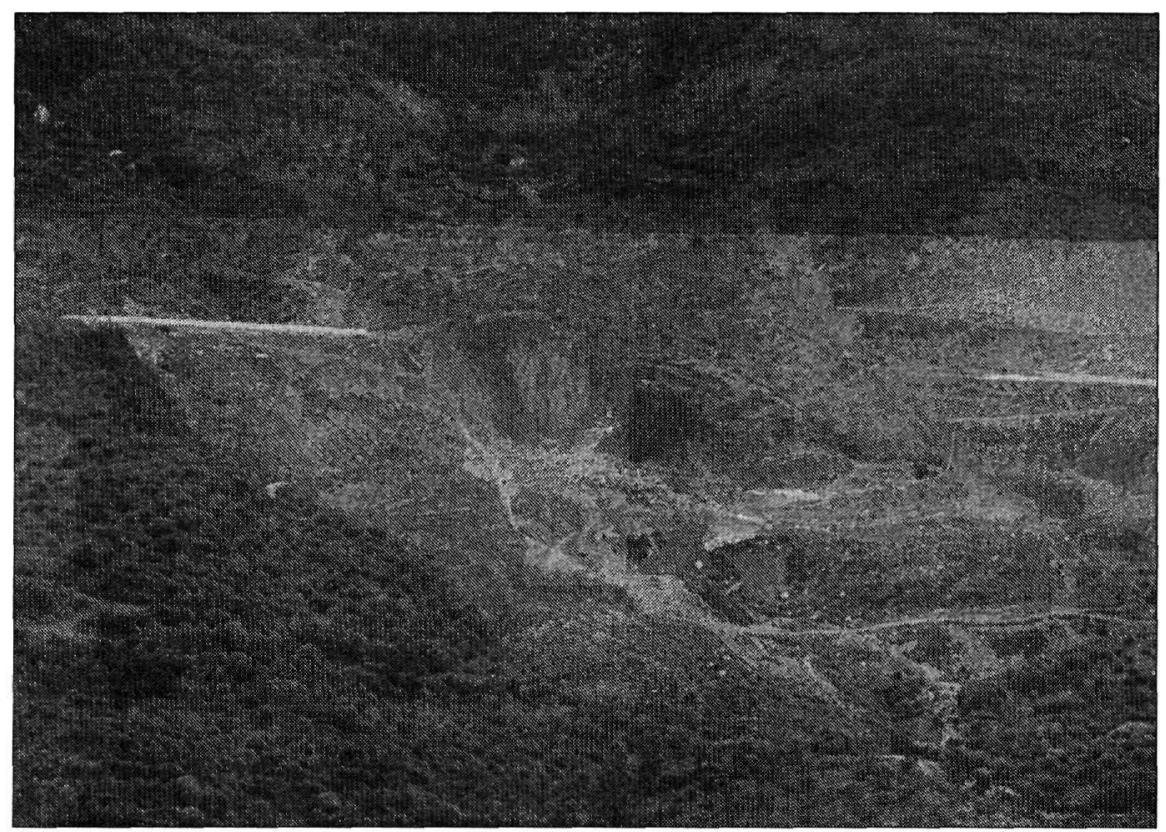

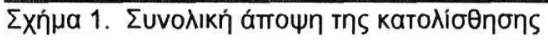

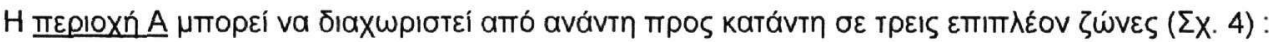

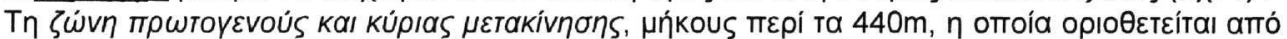

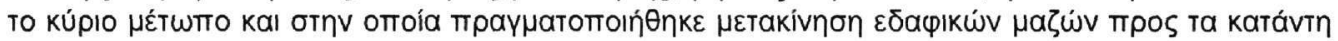

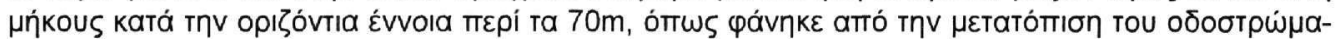

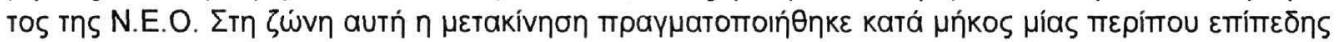

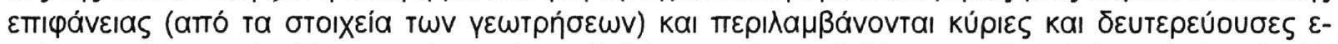

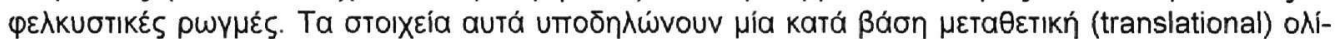

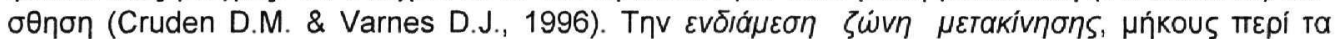

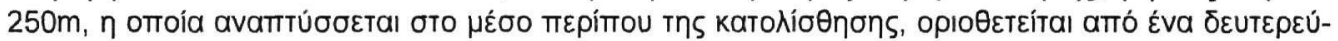

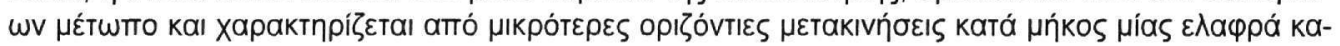

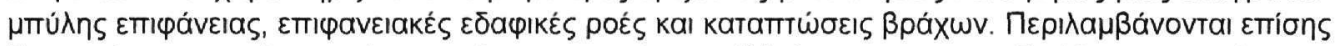

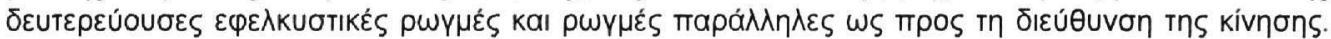

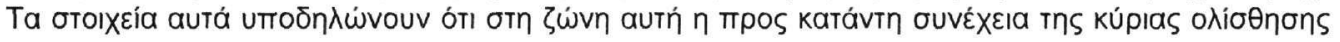




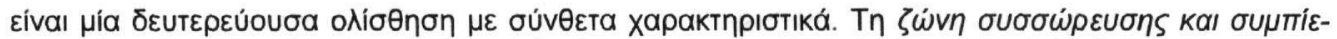

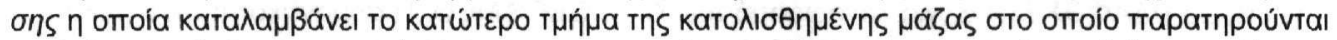

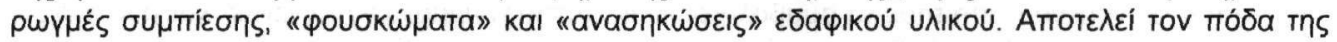

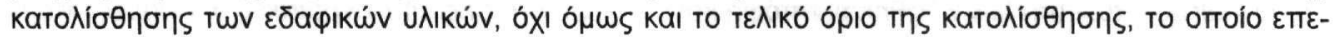

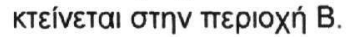

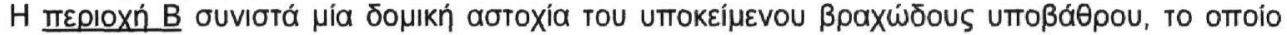

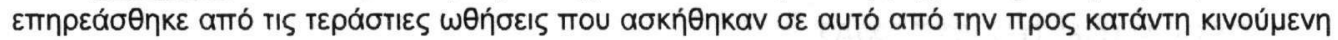

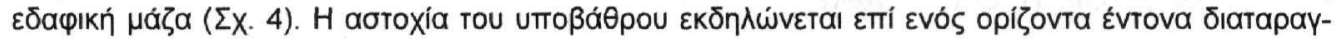

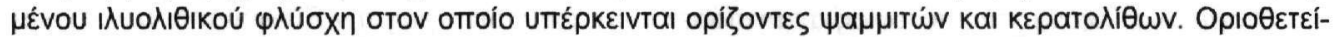

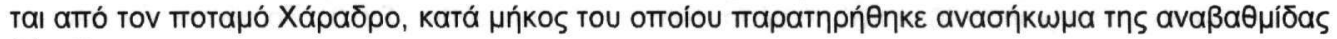
( $\Sigma x .5)$.

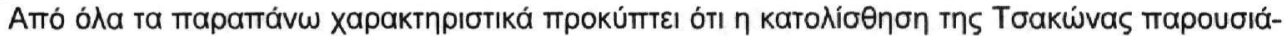

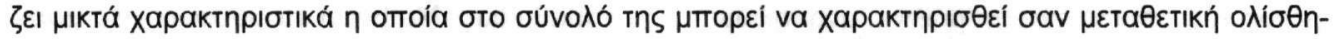

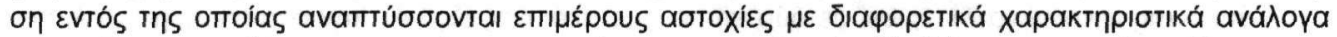

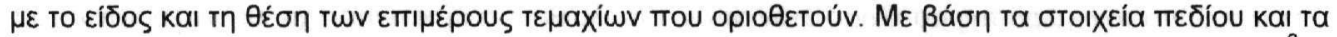

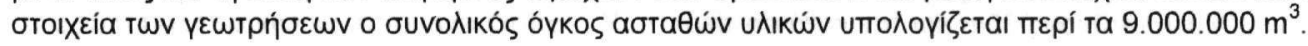

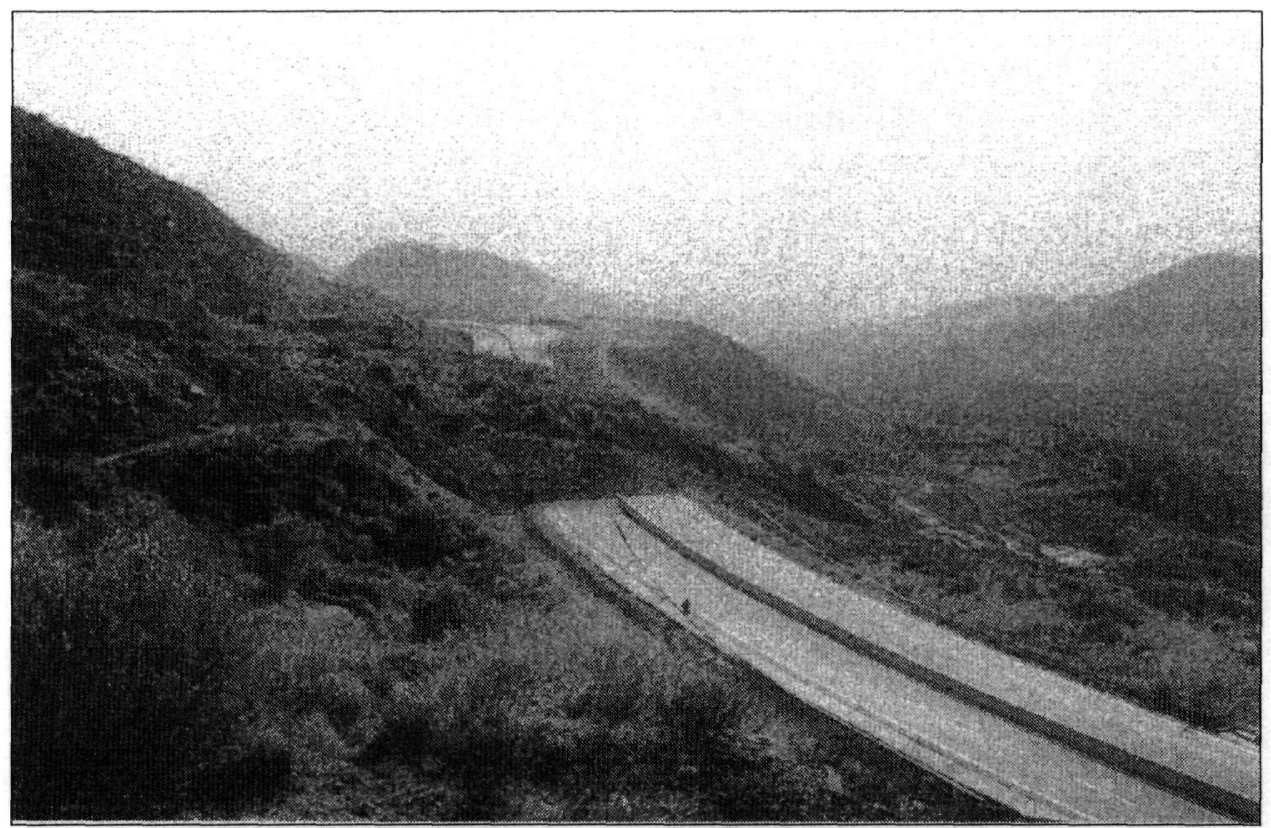

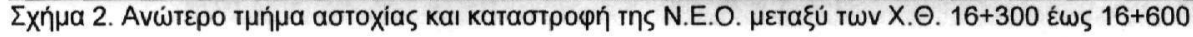

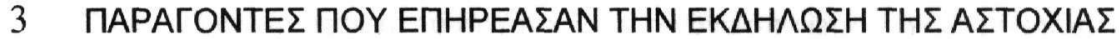

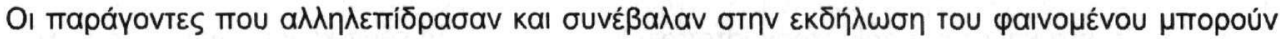

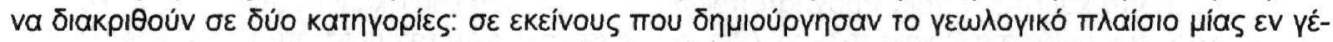

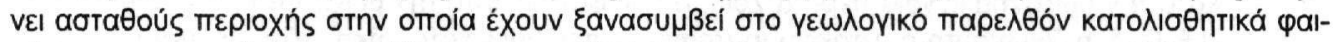

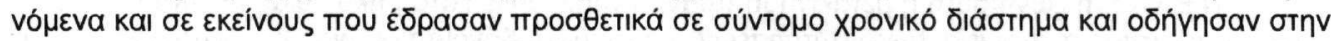

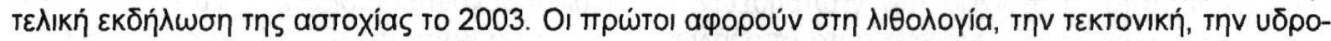

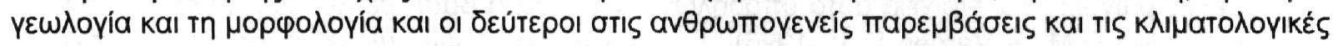

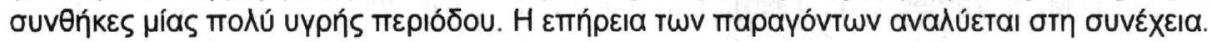




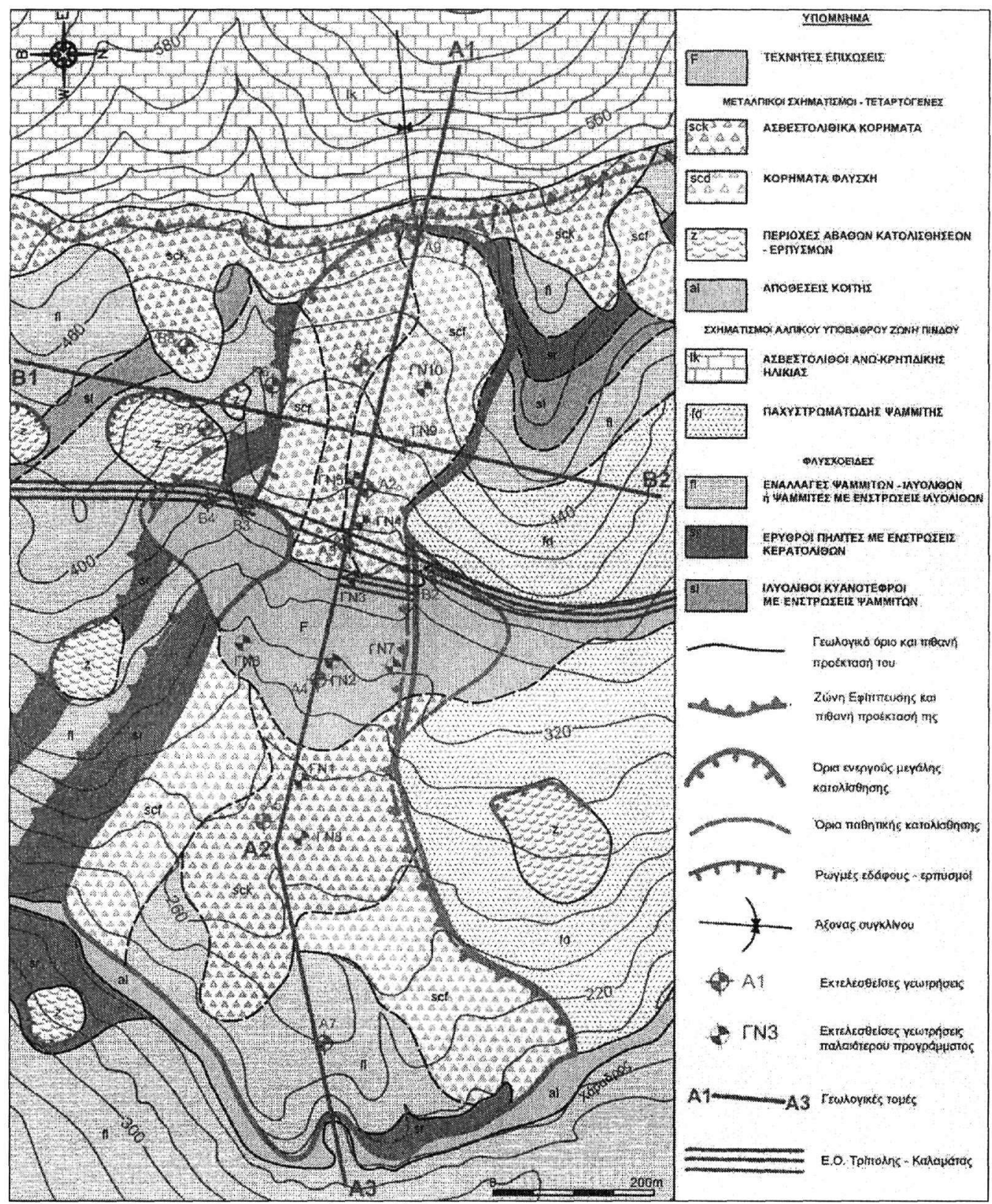

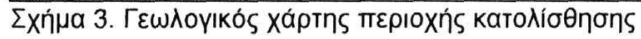

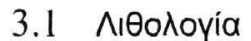

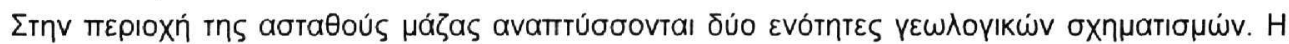

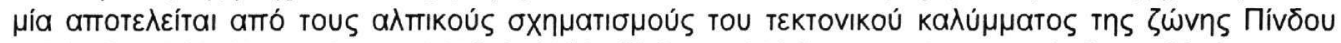

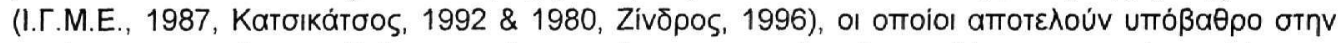

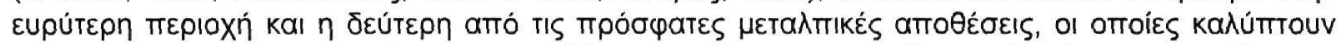

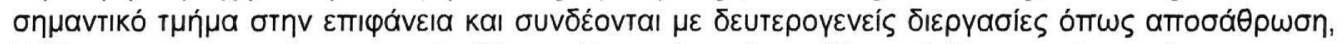

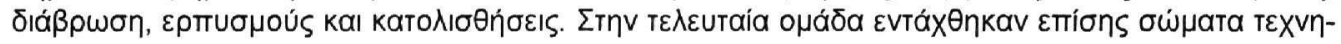

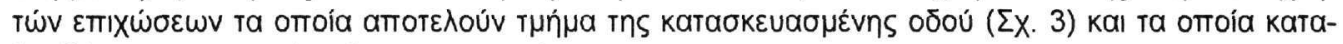

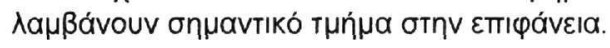




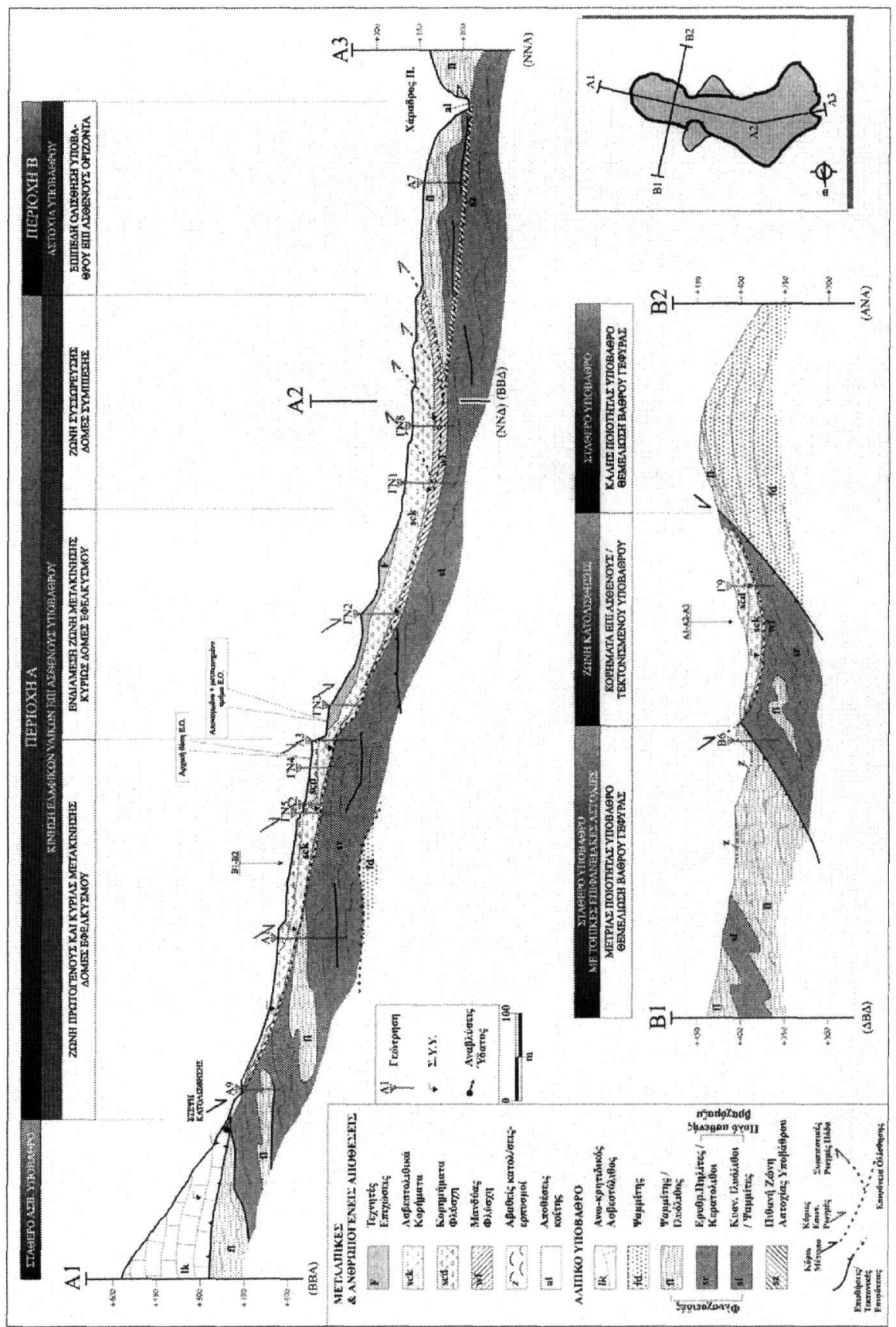

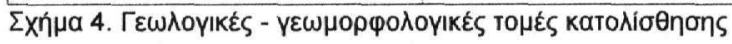

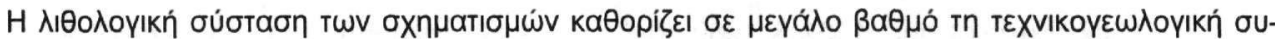

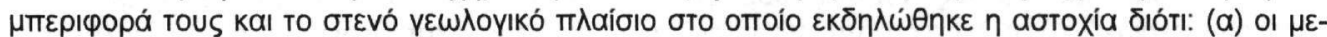

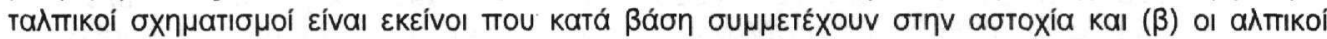

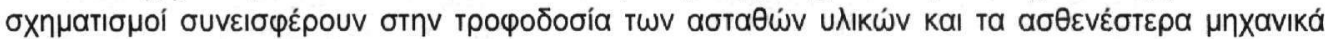

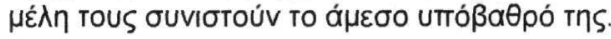




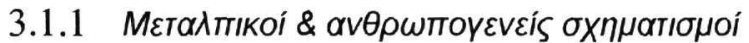

\subsubsection{TEX T}

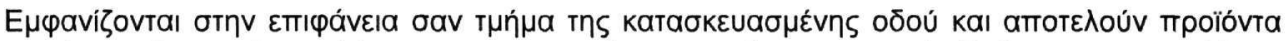

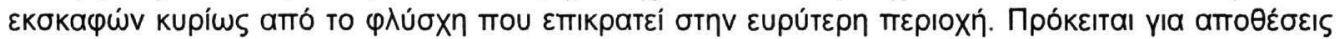

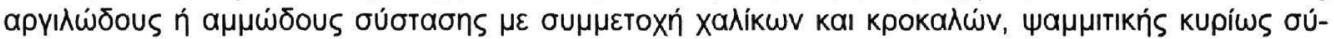

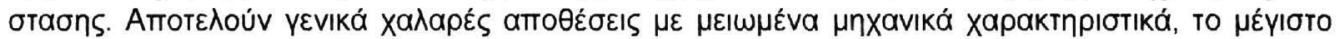

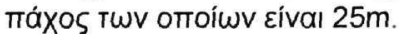

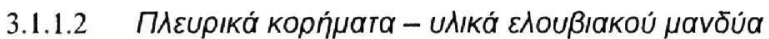

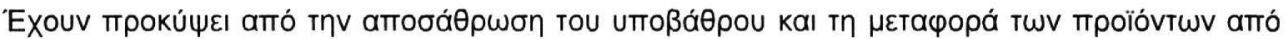

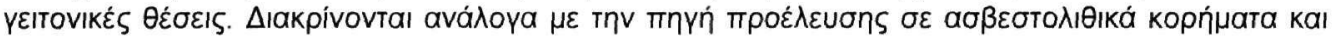

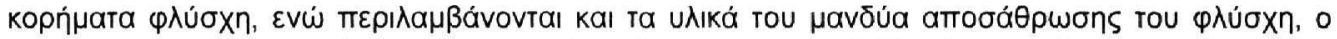

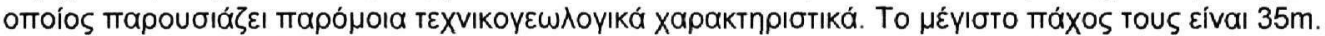

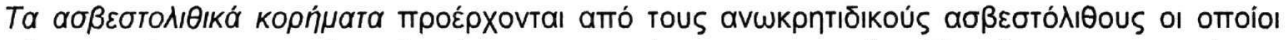

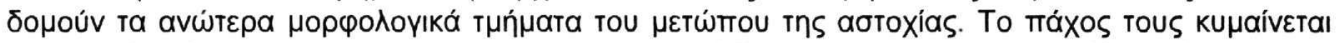

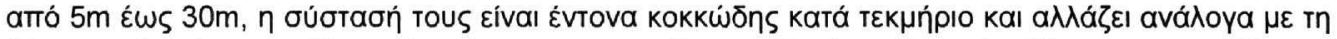

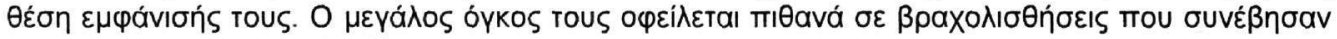

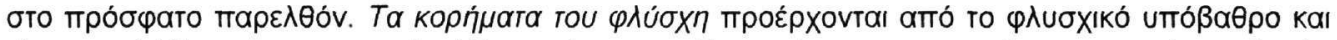

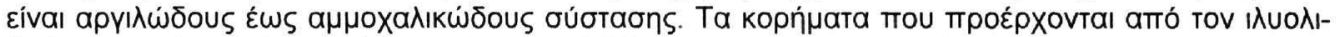

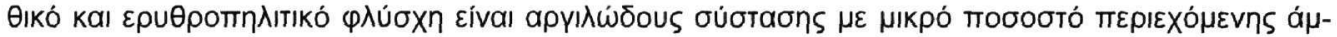

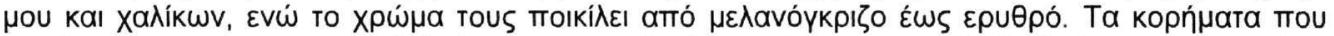

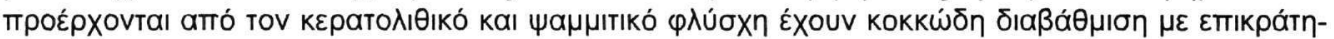

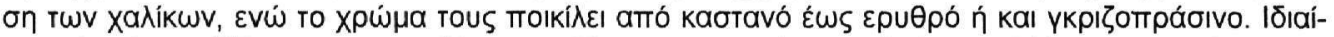

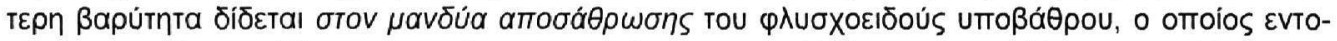

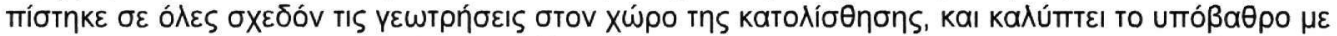

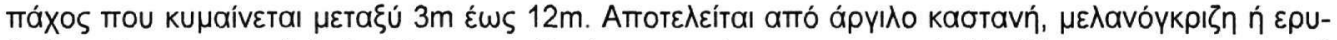

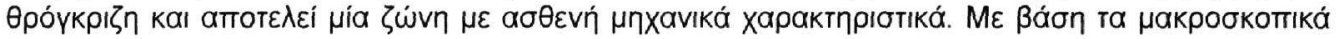

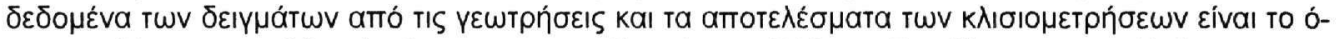

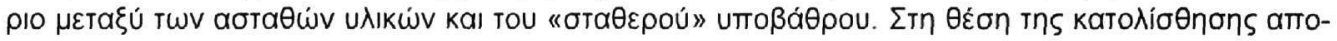

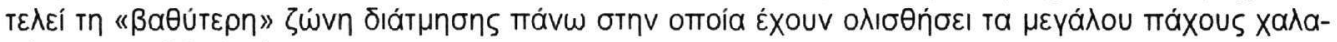

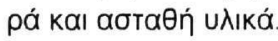

\subsection{2 Аגтাкó uாт́ß $\alpha \theta \rho o$}

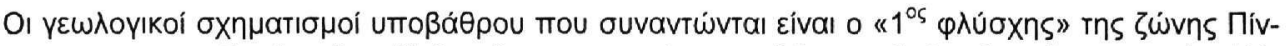

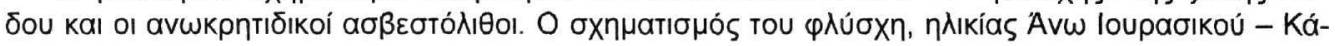

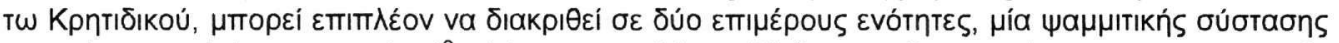

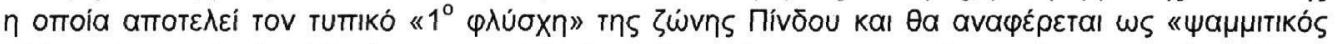

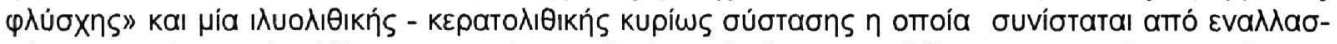

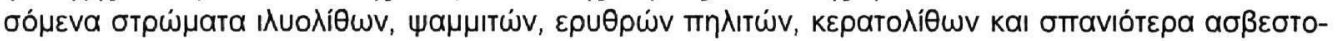

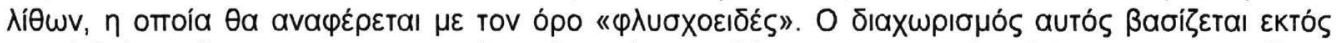

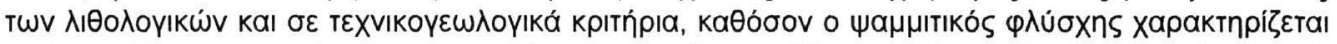

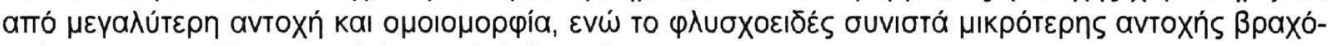

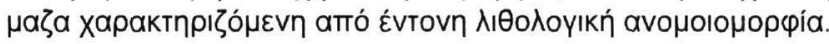

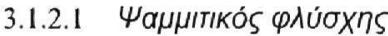

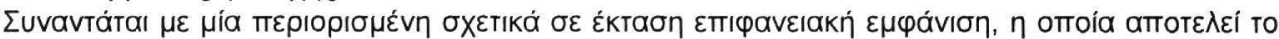

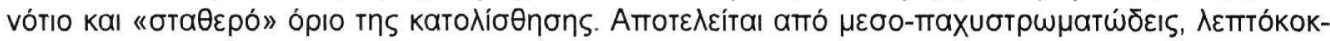

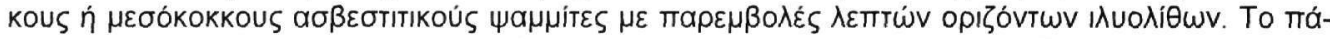

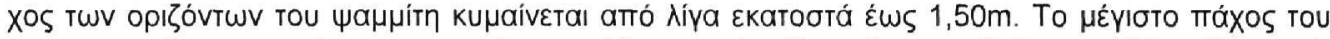

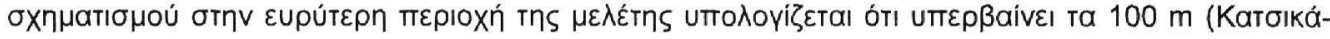

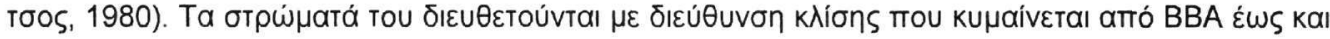




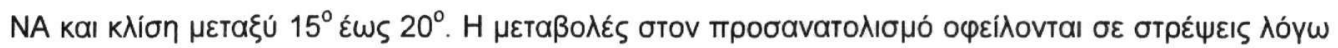

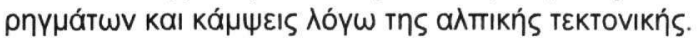

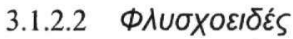

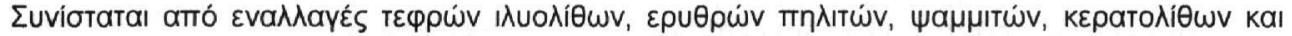

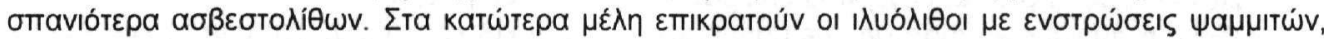

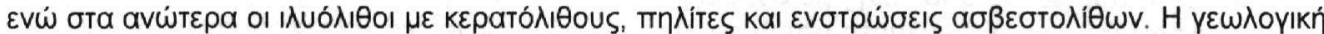

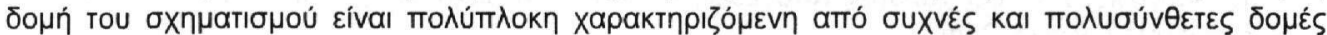

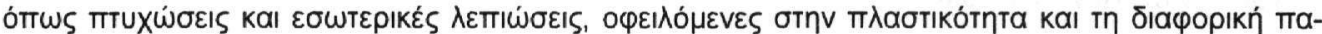

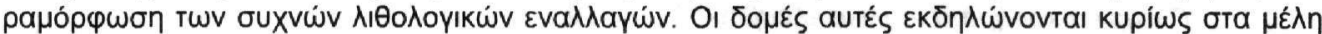

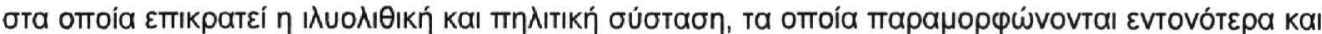

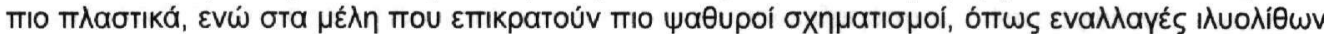

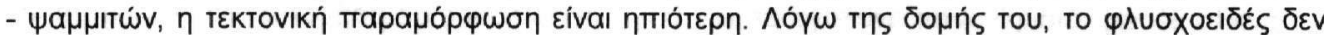

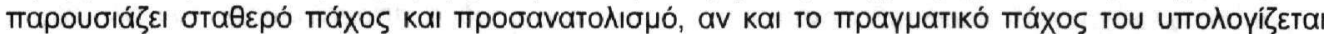

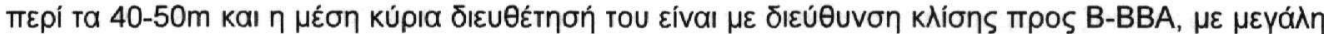

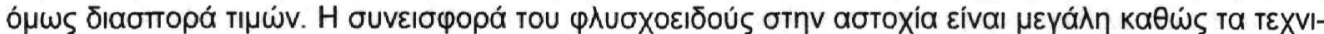

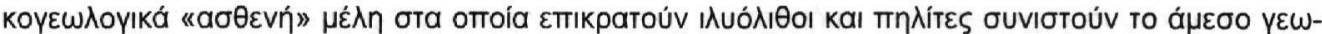

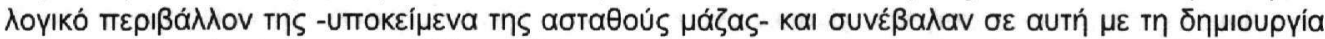

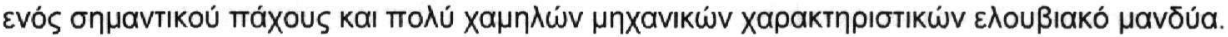

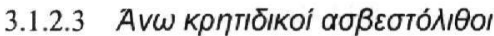

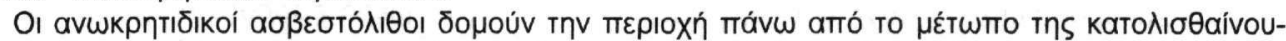

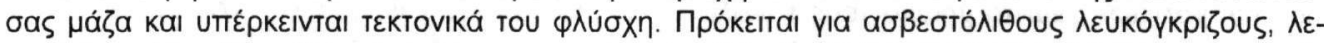

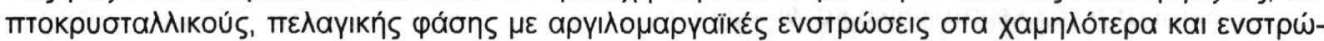

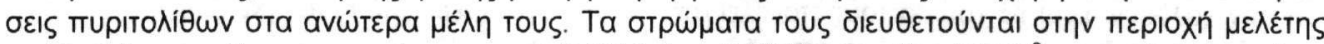

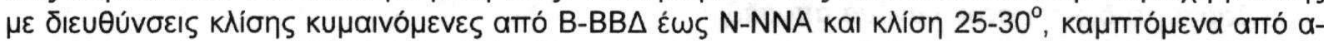

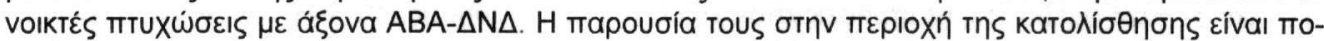

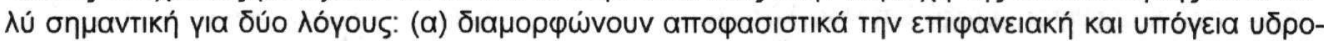

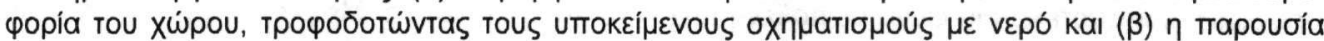

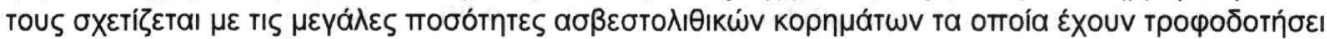

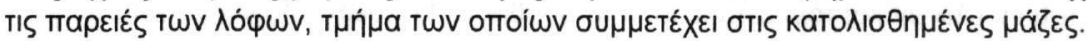

\section{2 ТЕктоVIкń}

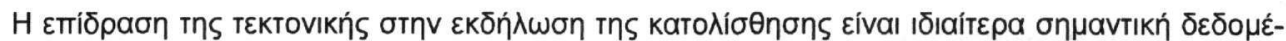

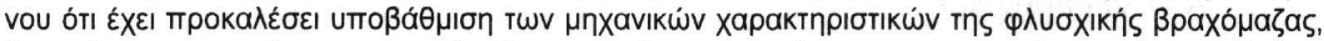

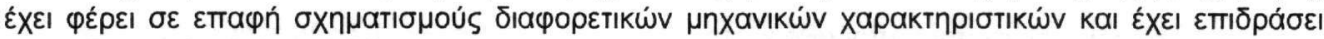

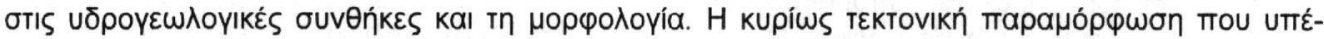

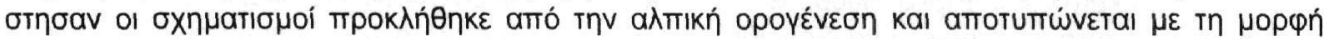

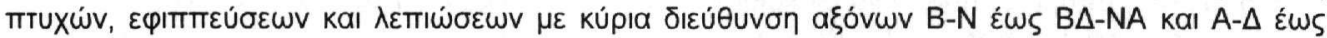

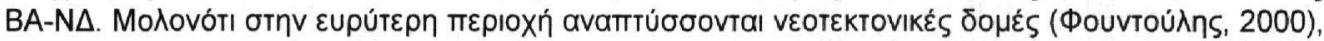

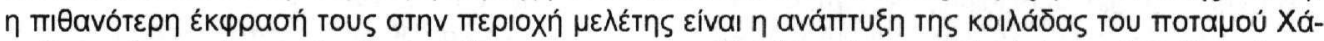

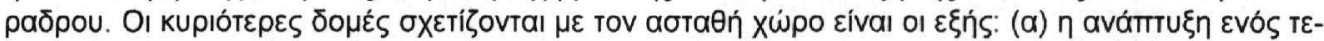

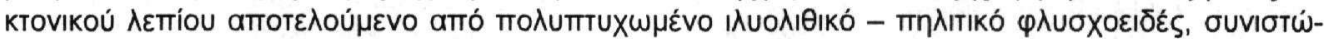

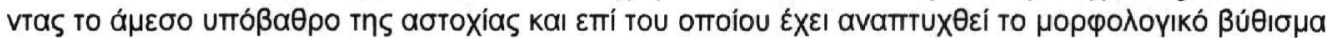

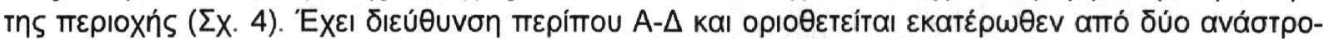

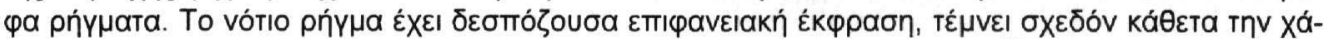

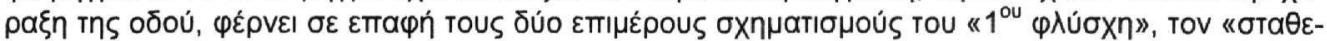

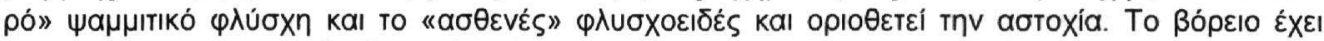

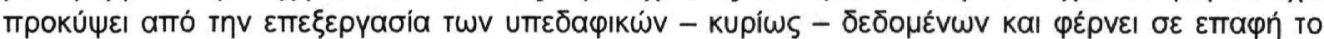

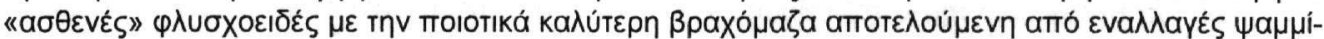

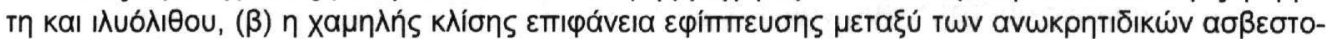

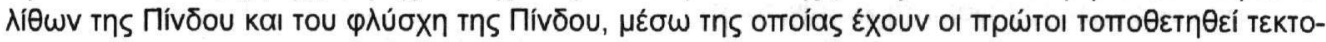

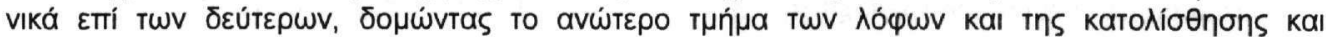

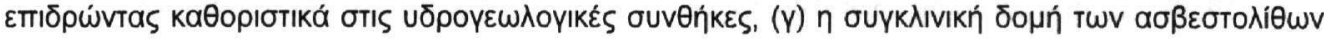




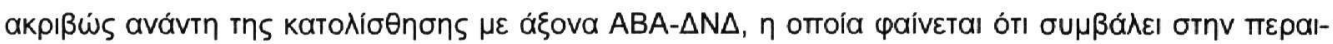

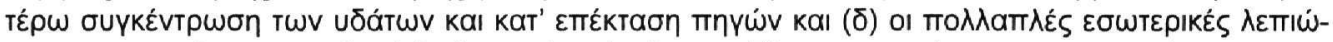

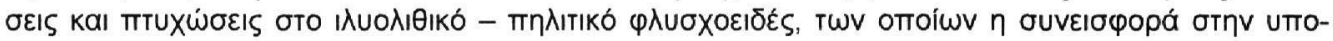

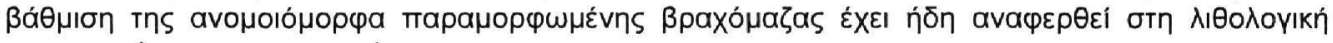

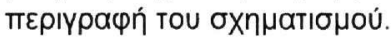

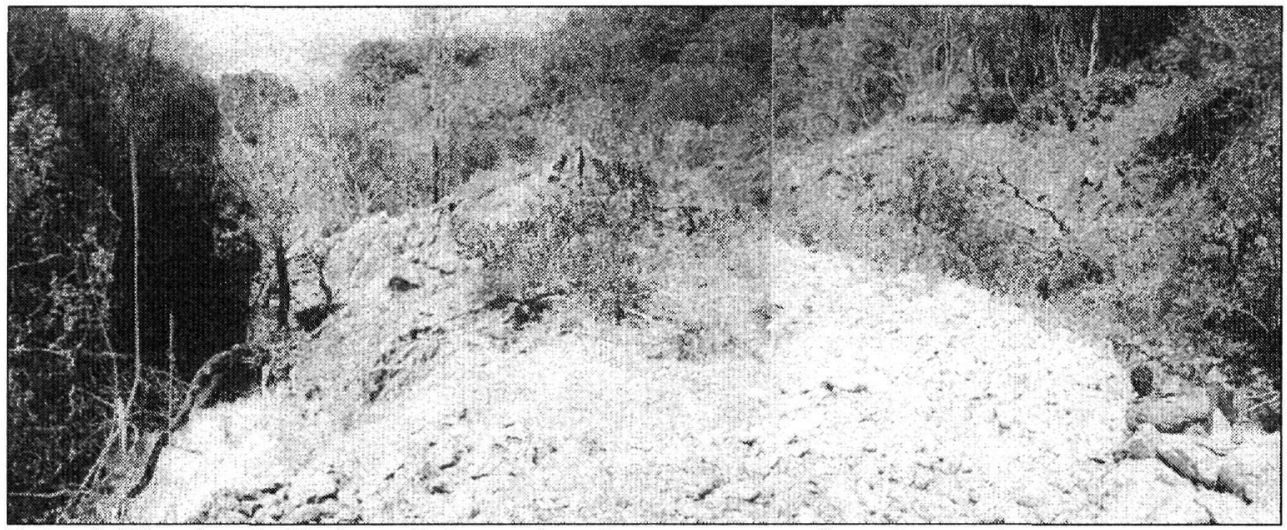

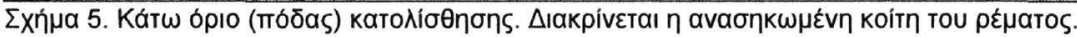

\subsection{Mорчолоүía}

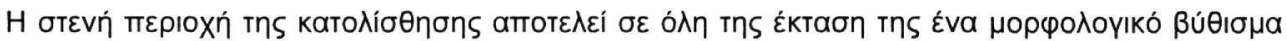

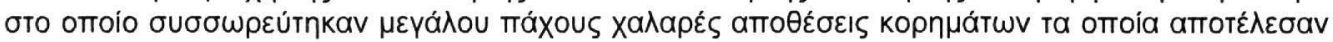

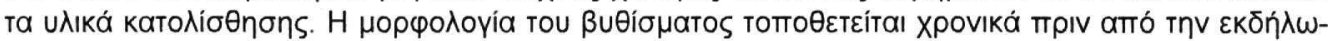

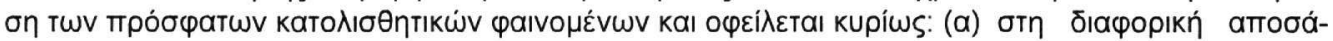

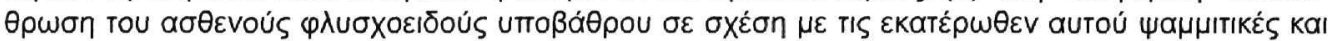

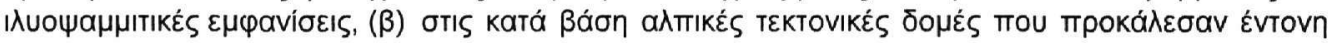

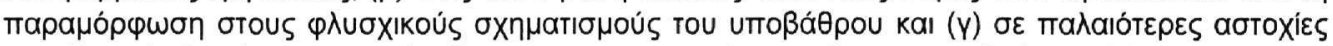

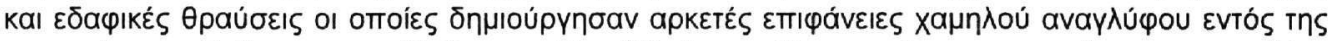

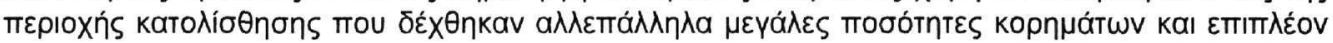

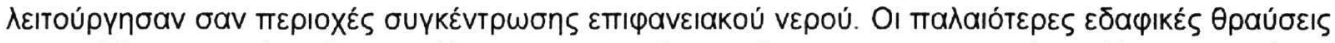

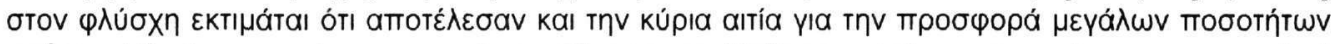

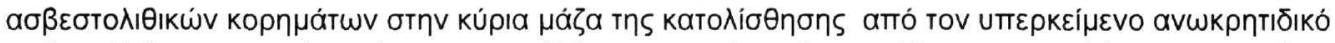

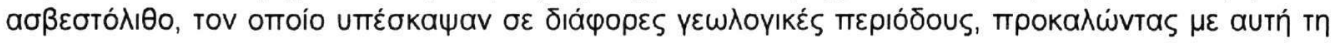

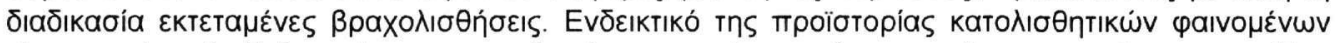

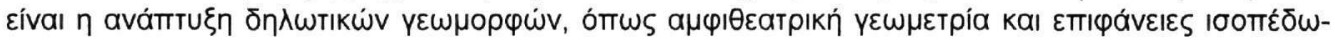

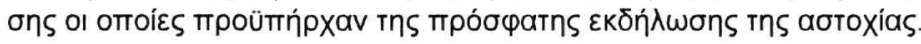

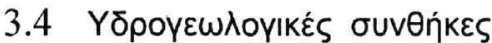

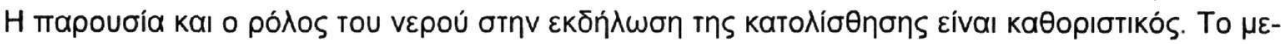

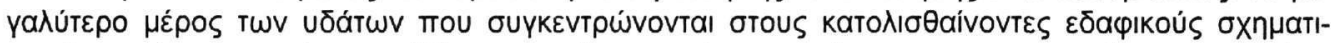

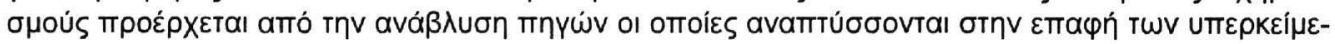

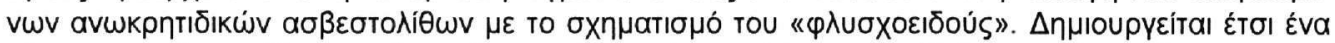

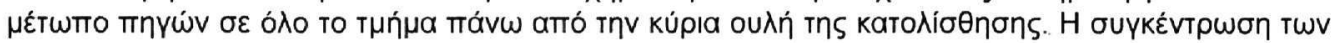

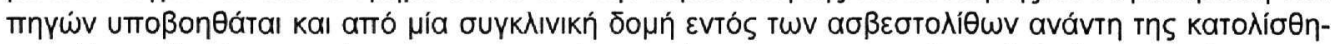

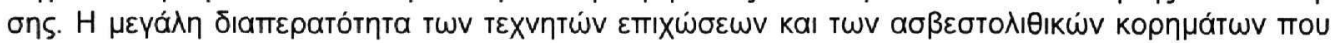

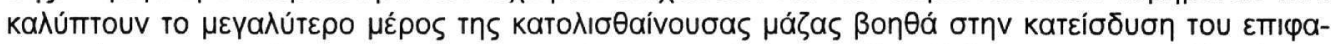

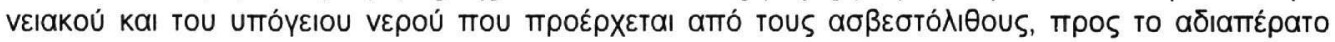

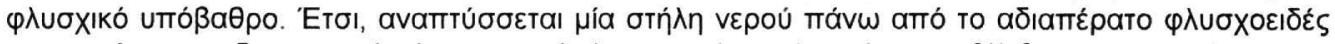

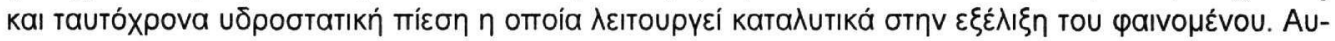

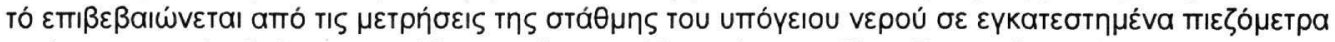

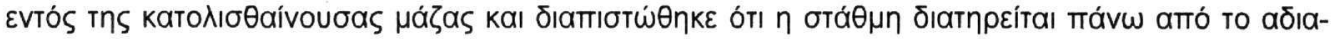




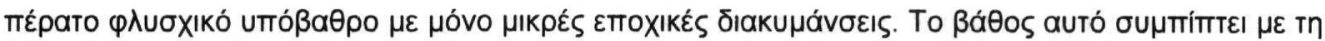

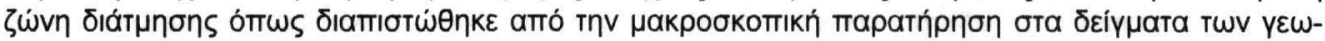

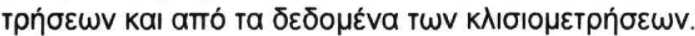

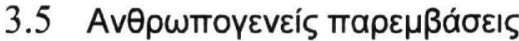

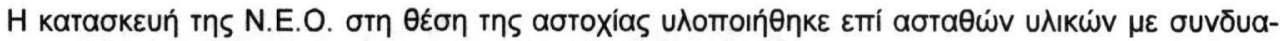

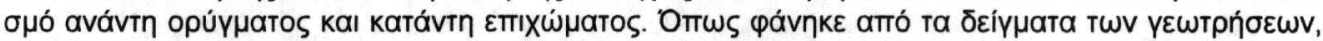

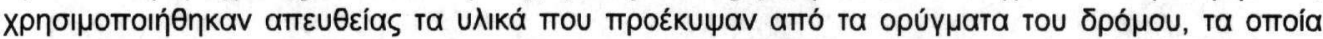

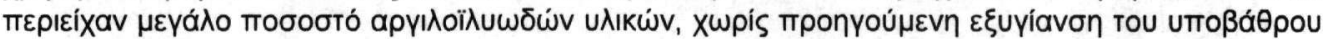

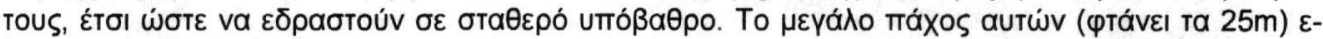

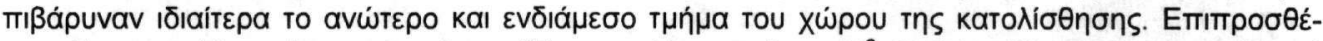

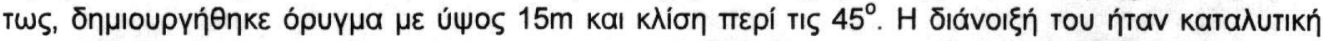

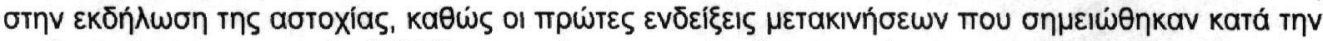

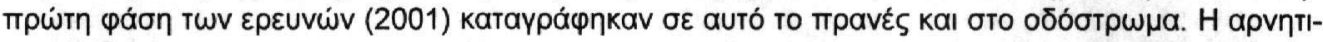

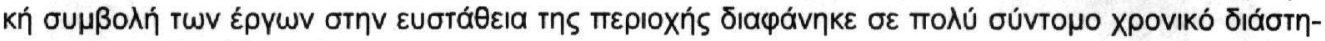

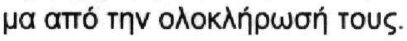

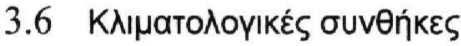

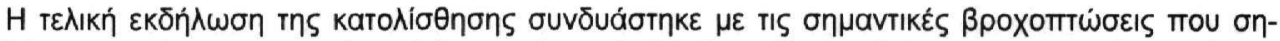

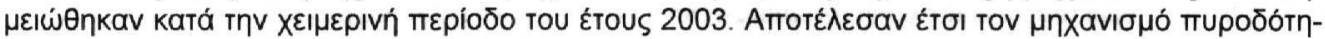

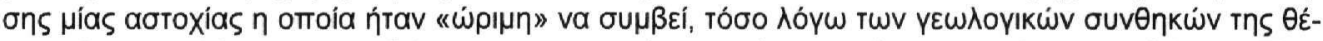

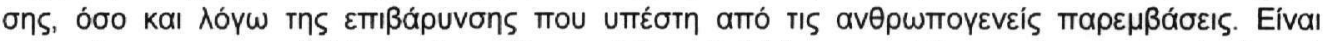

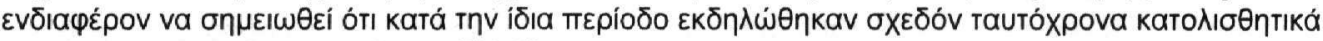

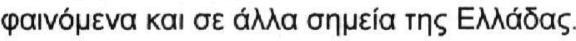

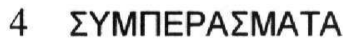

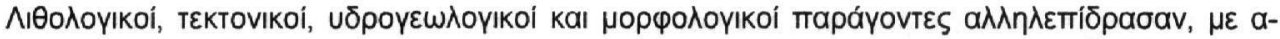

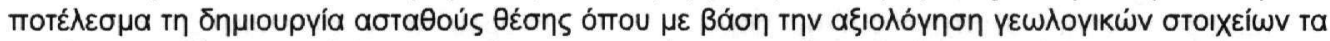

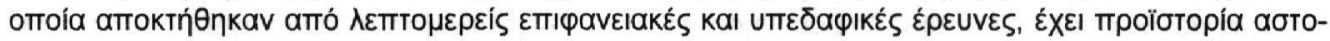

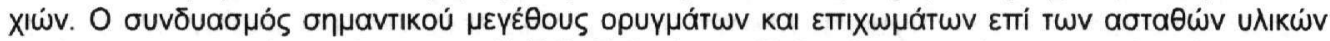

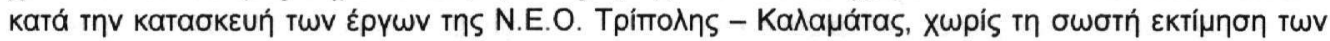

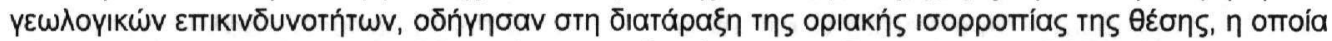

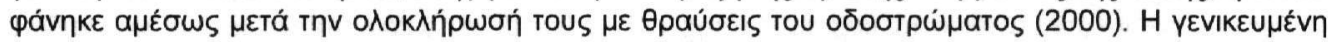

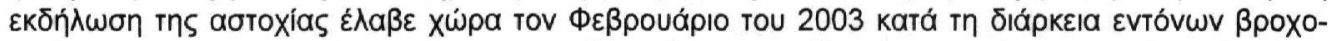

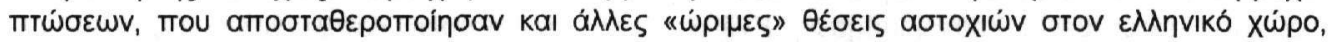

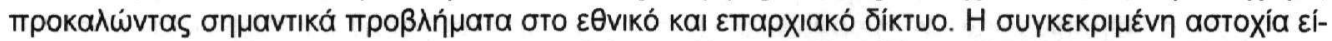

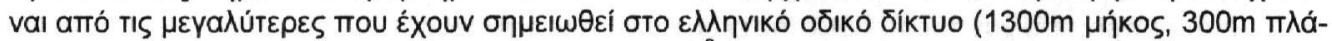

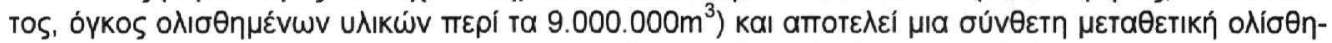

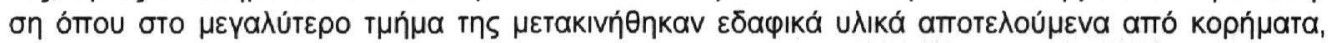

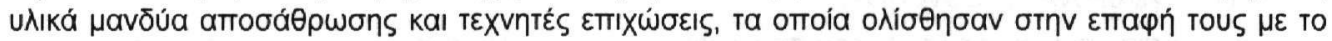

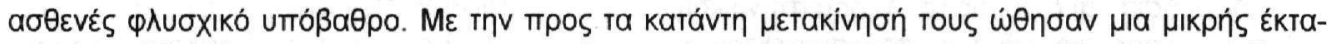

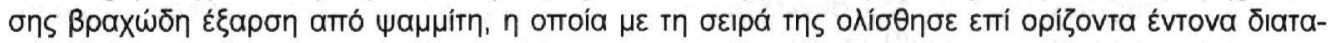

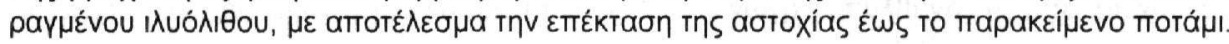

\section{ANAФOPE $\Sigma$}

Cruden D.M. \& Varnes D.J. 1996. Landslide types and processes. In Special Report 247: Landslides. Investigation and Mitigation., TRB (A.K. Turner \& R. Schuster, Eds.), National Research Council, National Academic Press, Washington, D.C., pp. 36-75.

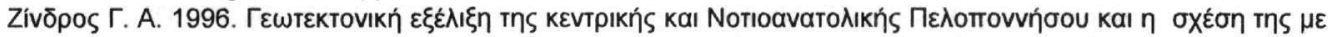

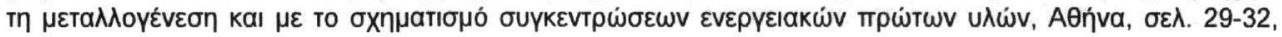
63-73.

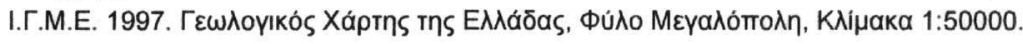




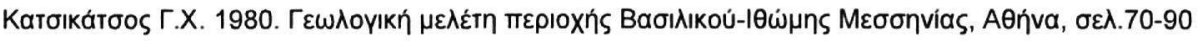

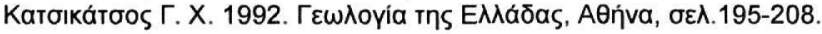

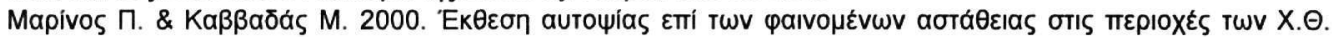

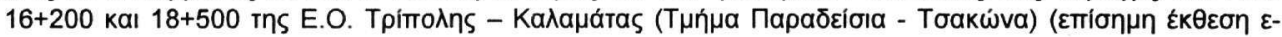
$\mu \pi \varepsilon ı \rho$ үvïuova).

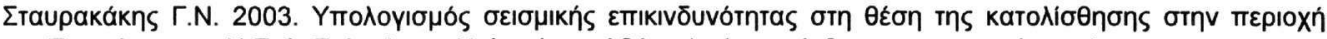

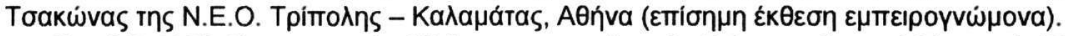

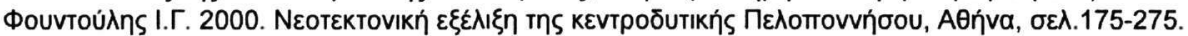

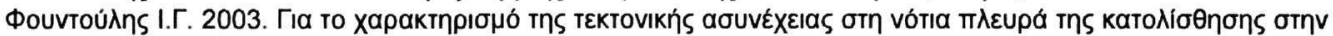

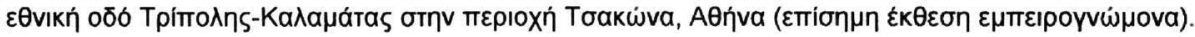

\section{ABSTRACT}

\section{LANDSLIDE AT TSAKONA AREA IN ARKADIA PREFECTURE. GEOLOGICAL CONDITIONS AND ACTIVATION MECHANISM}

Sotiropoulos L., Liberis E., Sigalas A., Ntouroupi A., Provia K. \& Dounias G. Edafos Engineering Consultants LTD, Ypereidou 9, 105 58, Athens, edafos@hol.gr

The geological conditions of the landslide's area, at Tsakona, in Arkadia Prefecture, are examined, as well as the factors that influenced the landslide's evolution. The landslide occurred at a distance of $15 \mathrm{~km}$ south of Megalopoli, on the New Highway, connecting Tripoli to Kalamata and constitutes one of the larger road landslides that have ever taken place. It occupies an area of a length of $1200 \mathrm{~m}$ and a width of $300 \mathrm{~m}$. Geotectonically the landslide's region is placed in a block of the Pindos zone, thrusted on the Gabrovo-Tripoli zone. The geological formations that comprise the closer geological frame, consist of the formation of "First Flysch", Upper Jurassic - Lower Cretaceous and of the Upper Cretaceous limestones. The geological factors that drastically influenced the landslide's activation are lithological, tectonic, hydrogeological and morphological. The mainly siltstone lithology of the flysch, the intense tectonic deformation that occurred during the alpidic horogenetic phase, the morphological depression that is formed by the landslide's region and the large quantities of groundwater supplied by the uphill limestone, are the main geological reasons that activated the landslide. It should be emphasised that the activation and evolution of the landslide were greatly influenced by human activity during the road construction. 